\title{
Pressure Sensor Device
}

National Cancer Institute

\section{Source}

National Cancer Institute. Pressure Sensor Device. NCI Thesaurus. Code C50167.

A sensor designed to respond to the level of pressure in a space or pressing on a surface. 